\title{
LA TRADUCCIÓN LITERARIA: HACIA UNA ADECUACIÓN DE ELEMENTOS PAREMIOLÓGICOS
}

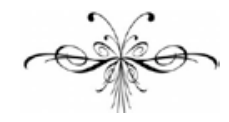

SALUD M $M^{\mathrm{a}}$ JARILLA

Resumen: La traducción de una obra literaria presenta unos problemas muy concretos causados por la forma y el contenido del mensaje. Hay que tener en cuenta la función de los textos, sus destinatarios, la relación entre las culturas de los dos pueblos, su condición moral, intelectual y afectiva, así como los factores del tiempo y lugar que pueden afectar tanto al texto de origen como al texto de llegada. La traducción de elementos paremiológicos es bastante compleja, debido al alto contenido de información sociocultural implícita. Es muy importante que el traductor posea una gran competencia paremiológica que le permita identificar dicha unidad en la lengua de partida y, si es posible, además encontrar su correspondencia en la lengua meta. La lengua española es rica en expresiones, modismos, refranes, etc. y todo ello queda reflejado en los clásicos de la literatura española, muchos de los cuales poseen un elevado número de elementos paremiológicos; representan unas parcelas muy características de una sociedad específica y un pueblo concreto. En este trabajo, vamos a analizar algunos ejemplos de cómo adaptar este tipo de expresiones. Siguiendo las teorías que explican distintos procesos pretendemos reflexionar sobre la función de los elementos paremiológicos y qué soluciones ha tomado el traductor. Recordaremos algunos ejemplos de la traducción al italiano de elementos paremiológicos extraídos de la obra de Miguel Delibes.

Palabras claves: Traducción literaria. Paremiología. Análisis crítico.

\begin{abstract}
The translation of a literary work poses very specific problems caused by both the form and content of the message. One must take into account the role of texts, their readers, the relationship between the cultures of the two peoples involved, their moral, intellectual and emotional condition, as well as factors such as time and space, which can affect both source and target texts. The translation of paremiological elements is quite complex due to the high content of implicit sociocultural information in them. It is very important for translators to possess a great paremiological knowledge which should help them recognize said unit in the source language and, if possible, to also find its correspondence in the target language. The Spanish language is rich in expressions, idioms, proverbs, etc. and all of this is reflected in the classics of literature, many of which exhibit a high number of paremiological units; and they represent characteristics very specific to a particular society and people. In this paper we will consider some examples of how to adapt this kind of expressions in translation. Following the theories that explain different processes, we intend to analize the role of paremiological elements in texts and the solutions taken by the translator in some examples of translation of paremiological elements taken from the literary works of Miguel Delibes.
\end{abstract}

Keywords: Literary translation. Paremiology. Critical analysis. 


\section{Hacia una teoría crítica. Fase de interpretación}

$\mathrm{E}$ l contenido de toda obra, de todo texto, de todo mensaje, en muchas ocasiones, se nos puede presentar como algo ambiguo, una región textual, en un principio, carente de sentido. Durante el proceso de interpretación y búsqueda de significación es cuando se concreta y persigue un sentido que, dentro de la situación comunicativa en la que se inserta, no genere extrañamiento y conserve su función. Como ya es bien sabido, la traducción ha sido, desde hace siglos, una importante forma de conocimiento y transmisión de una cultura, de su literatura..., y su ejercicio, además, ha contribuido a la creación de nuevas formas y géneros, nuevos modelos, etc...

El traductor se halla en el centro de un proceso dinámico de comunicación como mediador en el productor de un texto original y quienes resulten ser sus receptores en la lengua de llegada. (HATIM, B y MASON, I., 1995, pág. 281)

La traducción según García Yebra ${ }^{1}$ es un proceso que consta siempre de dos pasos. En un primer lugar está la comprensión del texto de origen y posteriormente la fase de expresión del contenido del mensaje en la lengua terminal. En esta fase de comprensión es donde el traductor se pregunta a cerca del significado del texto original y es aquí cuando los elementos paremiológicos son analizados para lograr una correcta comprensión. En el momento del primer acercamiento a un texto literario el traductor es ante todo un lector y, posteriormente, interprete; leeinterpreta en la lengua de origen lo que más tarde, a través de un largo proceso de codificación será transvasado a la lengua de llegada o lengua meta.

Uno de los puntos importantes es el grado de contextualizaciones que rodea la producción de una obra literaria y su fijación en el tiempo dentro de unas coordenadas espacio-temporales concretas. En una traducción técnica, por ejemplo, el traductor pasa por una búsqueda de las normas de estilo que definen un texto científico, económico, etc, teniendo en cuenta la tipología textual, sin olvidarnos del publico receptor al que se dirige el mensaje para saber si utilizar un lenguaje más restrictivo (propio de una ciencia especializada) o divulgativo si se quiere dar a conocer al gran público. Como textos de referencia el traductor suele indagar y buscar textos producidos en las mismas condiciones, tanto el la lengua de origen como en la lengua meta y así analizar el lenguaje y las estructuras técnicas, a la vez que verifica si su texto puede se corresponder con los ejemplos de la especialidad.

Ahora bien, si partimos de estos principios documentales para una obra literaria, los puntos de análisis y búsqueda de procedimientos son mucho más amplios. Podemos llegar a necesitar muchos textos de referencia, y de muy distinta índole.

Un punto de partida sería una búsqueda en manuales o historias de la literatura a cerca de la descripción del estilo y género que delimitan nuestra obra. Estas obras de referencias nos clasifican y delimitan a un autor y una obra en un género y un período histórico determinado. Aún así el autor, en muchas ocasiones, transgrede los patrones establecidos por la convención haciendo alarde de su genialidad. Conocer la obra entera del autor, además, nos puede ayudar en algunas estructuras complejas para lograr descubrir si se trata de una estrategia recurrente o sólo ha sido

\footnotetext{
${ }^{1}$ Cfr. V. García Yebra, Teoría y práctica de la traducción, vol I, Madrid, 1997. p. 33.
} 
un caso puntual de transgresión a la norma. Y así sucesivamente la tarea se va complicando al ampliar nuestro campo de investigación para solventar posibles problemas traductológicos.

Conocer detalles biográficos se perfila como algo crucial para la búsqueda de posibles analogías. Los ambientes donde vivió, el momento histórico, sus contactos con el mundo diario y sus fuentes, abren un abanico de contextos muy difícil de individualizar.

No podemos olvidar que el momento ideológico en que se crea una traducción, normalmente, marca las pautas a seguir por el traductor para realizar su trabajo y en este aspecto: "dicta las soluciones a los problemas relacionados tanto con el 'universo del discurso' del original como con la lengua en la que está inscrito ${ }^{2}$."

En definitiva, el resultado final del proceso de traducción se simplifica en una decodificación del lenguaje de un texto y su nueva codificación teniendo en cuenta el horizonte de aceptación lingüístico de la cultura receptora de dicha traducción. En una traducción literaria nos encontramos ante una actividad hermenéutica que implica, por tanto, una interpretación profunda de distintos factores, más cercanos a un análisis crítico de la obra.

Si tomamos como punto de partida los supuestos hermenéuticos de Szondi para aplicarlos al ejercicio de la traducción, se pueden apreciar dos modelos de interpretación:

El primero de dichos modelos podría ser lo que Szondi ${ }^{3}$ denomina Interpretación Gramatical, de ámbito lingüístico, cuya finalidad o cometido consiste en la modificación de aquellas expresiones o "signos", que el tiempo ha convertido en obsoletos y carentes de significado, por otros nuevos o por una explicación que justifique la permanencia de esos referentes estructurales. Y el otro modelo sería una Interpretación Alegórica ${ }^{4}$ basada en la posibilidad de desentrañar múltiples significados allá donde el estudio lingüístico no es suficiente, ya que dichos elementos se alejan de las reglas gramaticales. Este segundo tipo de interpretación enriquece el resultado final dando importancia a todo un universo de menciones y significaciones. La fase de Interpretación Alegórica sería la encargada de determinar la función y las posibles soluciones ante los diversos elementos paremiológicos. Dichos elementos por sus implicaciones socio-culturales necesitan algo más que la aplicación de unas reglas gramaticales para poder aclarar sus significados y funciones dentro de un discurso literario concreto.

\footnotetext{
${ }^{2}$ Véase el capítulo Traducción: las categorías en Traducción, reescritura y la manipulación del canon literario. André Lefevere (1997), Ediciones colegio de España, Salamanca.

${ }^{3}$ Para este breve planteamiento teórico hemos utilizado como obra de referencia el volumen de Szondi (1929-1971) Introducción a la hermeneútica (1975), Abad Editores, 2006, Madrid. Es una obra póstuma que teniendo en cuenta su formación y su conocimiento de la estética alemana romántica e idealista supone un texto fundamental para la consagración de una hermenéutica literaria. Su autor pretende dar respuesta a si, en su época de redacción, se podía considerar la existencia de una hermenéutica literaria, alejada de la metodología más tradicional del ars interpretandi.

${ }^{4}$ En la obra de Sonzi encontramos también la denominación de Interpretación Técnica o interpretación psicológico-técnica (tomada del Esbozo sobre la Hermeneútica de Schleiermacher 1805) para denominar un tipo de interpretación que toma el discurso como un acto del individuo pensante y por lo tanto está sujeto a principios de individualidad donde se entrelazan pensamientos e imágenes, ligada además a modificaciones particulares de la lengua y de la composición de la obra, opuesta por tanto a la denominada interpretación gramatical. Véase capítulo 10, íbidem, pp 211-230.
} 
El paso del tiempo, además de alejarnos del sentido original de la obra y de dichos elementos culturales, ha eliminado, en muchos casos, el uso de un elemento paremiológico que era algo obvio para una época y una cultura determinada y se ha convertido en una estructura carente de significado para el estudioso que se enfrenta a su análisis. Esta interpretación es, en definitiva, la suma de un gran número de implicaciones que el tiempo va añadiendo y ampliando al sentido de la obra original.

La fase de interpretación que estamos escudriñando supone un importante reto a la hora de desenmarañar todos los significados de la obra literaria, y se necesita pues un criterio y unas bases teóricas ya que el resultado final depende directamente de este momento de análisis ideológico-estructural. La intención de mantener algunas trazas de la estructura lingüística original de la obra se enfrenta, en muchas ocasiones, con el paso del tiempo, a un cambio en las directrices teóricas y, además, no debemos olvidar que el objetivo principal de la traducción o trasvase es adecuar un texto a otro ambiente geográfico, lingüístico y cultural diferente del momento de redacción y recepción del texto original. La obra a estudio en este breve trabajo, Señora de rojo sobre fondo gris ${ }^{5}$, no se encuentra muy alejada geográficamente, lingüística y culturalmente.

Los procesos traductológicos definidos por la teoría de la traducción que sirven de principios convencionales (transposición, modulación, equivalencia, adaptación, compensación,... ${ }^{6}$ ) son herramientas indispensables junto con una serie de reglas aplicables a dicho ejercicio, pero, no debemos olvidar que hay obras que, por su complejidad en cuanto a género y estilo, se alejan considerablemente de la convención y permiten un margen de actuación mucho más amplio. El traductor en la fase de análisis de una obra literaria debe tener en cuenta distintos procedimientos y estrategias $^{7}$ que no pongan en peligro la carga semántica del texto.

$\mathrm{Y}$ esto ocurre muy a menudo en los textos literarios donde al analizar el proceso de creación percibimos, en muchos casos, un alejamiento de las normas lingüísticas convencionales; frente a estos textos se necesitan, como hemos visto, otra serie de estudios y planteamientos de problemas, más cercanos a la crítica literaria preocupada por el estudio semántico que ayude a desentrañar algunos sentidos recónditos, como ocurre con los elementos paremiológicos.

Cuando buscamos significados en una obra literaria hay muchos factores propios de una cultura y un lugar concreto que identifican y expresan la esencia e identidad de los pueblos ${ }^{8}$. El conocimiento de estas estructuras, y sobre todo de la función lingüístico-cultural que realizan dentro de determinadas obras literarias, es imprescindible para, en un primer momento localizarlas, después decodificarlas y por último buscar, si es posible, otra expresión o elemento equivalente en el texto traducido que provoque en los lectores de la lengua de llegada un efecto similar al recibido por el lector de la lengua de origen. Entre estas estructuras tendríamos en una primera instancia las expresiones idiomáticas y elementos paremiológicos mu-

\footnotetext{
${ }^{5}$ M. Delibes. Señora de rojo sobre fondo gris, Ed. Destino, Barcelona, 1991.

${ }^{6}$ La obra de Vinay y Darbelnet (1973) Stylistique comparée du français et de l'anglais estructura los distintos procedimientos traductológicos. Véase también Torres, E. (1994) Teoría de la traducción literaria, Síntesis, Madrid, pp. 127-138.

${ }^{7}$ Con estrategia nos queremos referir a todas esas técnicas y procedimientos que son necesarios para que el texto meta sea funcional en la cultura receptora. Véase M.C. Vidal. Traducción, manipulación, deconstrucción, ed. Colegio de España, Salamanca, 1995, pág 24.

${ }^{8}$ Véase Fernández, L.F. El papel de la cultura en el proceso traslativo y en la formación del traductor, en Traducción y cultura. El reto de la transferencia cultural, pág 62-63.
} 
chas veces adscritos a una región o una zona culturalmente determinada y cuya localización o comprensión se convierten en obstáculo difícil.

\section{Interpretación de los elementos paremiológicos}

Ante las expresiones idiomáticas y los elementos paremiológicos no es fácil primero, para el traductor, reconocer, en muchas ocasiones, que se encuentra ante una expresión que sólo es típica de una zona determinada, con unas características propias y un significado y una función concreta dentro del texto.

Una vez reconocida la expresión se enfrenta a un abanico muy amplio de posibilidades que se le muestran ante si para lograr no dañar ni el significado ni la forma. Así pues, ante esta clase de elementos, el traductor, siempre, debe andar con mucho cuidado y calibrar la repercusión que obtendrá al optar por una u otra solución. Podemos encontrar datos y connotaciones propias de una zona muy determinada o un registro concreto (lenguaje más coloquial o vulgar) e incluso pueden aparecer con modificaciones significativas que el autor haya querido reflejar a conciencia.

Es cierto que al transferir el mensaje insertado en una obra literaria se da más importancia al contenido que a la forma ${ }^{9}$, a excepción, claro está, del lenguaje poético. En muchas ocasiones la primacía de la forma en detrimento de su contenido ha dado lugar a obras literarias con un mensaje claramente distorsionado ${ }^{10}$ y poco apreciadas en la cultura de llegada

Las unidades paremiológicas son expresiones que se han ido consolidando en la lengua hablada y por ello, indiscutiblemente, su sentido prima ante su forma; por tanto, en el ejercicio de la traducción se optará por una equivalencia de significado. $^{11}$

Aunque utilicemos el nombre genérico de unidades paremiológicas, vamos a ver algunos ejemplos de locuciones y modismos.

Las expresiones idiomáticas o modismos debido a su particular estructura no suelen tener el mismo significado en la lengua de llegada y en muchas ocasiones pasan desapercibidas generando pérdida de sentido o dando un sentido distinto al que le corresponde. Son elementos que dan vivacidad y agilidad; en muchas ocasiones aproximan el discurso a un lenguaje más común y comprensible. Estas estructuras obedecen a criterios de fijación (estructuras idiomatizadas y fijadas en una lengua) y forman parte de una lengua y una cultura concreta (en ocasiones ligadas a un momento histórico determinado y el paso del tiempo ha desgastado su uso y perdido su significado). Son por tanto, una marca popular y cultural muy difícil de traducir $^{12}$.

\footnotetext{
9 “No hay que transferir el mensaje de la lengua A a la lengua B simplemente en forma de núcleos inconexos”. En el lenguaje literario la forma del discurso juega un papel muy importante pero se tiende a priorizar el contenido del discurso sobre la forma y evitar así posibles distorsiones del mensaje o inconexiones que no ofrecen un sentido. Véase Nida, E.A. y Taber, CH. R. La traducción teórica y práctica, Ediciones cristiandad, Capítulo VI, pág. 142.

${ }^{10}$ Para una teoría sobre las fase de transferencia y sus problemas véase, Nida, E.A. y Taber, CH. R. La traducción teórica y práctica, Ediciones cristiandad, Capítulo VI, pág. 144.

${ }^{11}$ Cfr. J. Férnandez-Sevilla, Consideraciones lexicológicas y lexicográficas sobre el refranero en Estudios Románicos dedicados al profesor Andrés Soria Ortega, Ed. Universidad de Granada, Granada, 1985, p. 92.

${ }^{12}$ Cfr. Mendoza de Lima, L. ASELE. Actas VIII (1997) . La traducción de los modismos en la enseñanza del español como lengua extranjera. Centro Virtual Cervantes.
} 
Nida y Taber presentan tres tipos de modificaciones semánticas para que la pérdida de “contenido semántico” sea mínima ante tales expresiones:

a) Modificaciones de modismo a no modismo. A menudo estas expresiones se pueden cambiar por giros o expresiones que no son modismos.

b) Sustitución de un modismo por otro. Si el traductor conoce una expresión idiomática distinta, en lengua de llegada pero que tiene el mismo sentido y realiza la misma función puede optar por utilizarla.

c) De no modismo a modismo. Es la técnica que en traducción conocemos como Compensación ${ }^{13}$. Se utiliza cuando el proceso de traducción ha sacrificado un gran número de expresiones idiomáticas presentes en el texto de origen; el traductor puede insertar modismos en zonas donde en el texto de origen no existían y así tratar de compensar la carga idiomática y cultural presente en la obra original.

Muy brevemente vamos a mostrar algunos ejemplos de locuciones y modismos traducidos del español al italiano, para así comparar las soluciones aportadas por el traductor con los dos tipos de modificación semántica que proponen Nida y Taber, y con un tercero. Para ellos hemos optado por señalar algunos ejemplos dentro de la obra Señora de rojo sobre fondo gris de Miguel Delibes ${ }^{14}$ y su traducción italiana. ${ }^{15}$

Hay muy pocas traducciones al italiano de la obra de Miguel Delibes, algunas de las cuales sólo se encuentran disponibles en bibliotecas.

Delibes es uno de los autores contemporáneos españoles más representativos. En el año 1973 pasó a ser miembro de la Real Academia. Sus obras se han convertido en clásicos de la literatura española y, además, han pasado a formar parte de las lecturas obligatorias en la enseñanza en España.

è un autore la cui complessità linguistica spesso scoraggia il lettore. Pochi scrittori, infatti, sanno usare la lingua in tutte le sue sfumature come lui, che riesce a organizzare artisticamente, nei propri romanzi, i vari registri che caratterizzano l'ambiente in cui si muovono i personaggi, anche di umile origine, i modi di parlare di gruppo, i gerghi, i linguaggi delle generazioni e delle età, il linguaggio della politica... (SCELFO, 2000, pág. 121)

\section{Ejemplos de elementos paremiológicos y su traducción}

Teniendo en cuenta los distintos tipos de modificación semántica antes referidos vamos a analizar algunos ejemplos que nos ayuden a ilustrar algunos de los casos anteriores.

\footnotetext{
www.cvc.cervantes.es/ensenanza/biblioteca_ele/asele/pdf/08/08_0567.pdf

${ }^{13}$ Cfr. Vinay y Darbelnert (1958) Stylistique comparée du francais et de l'anglais. Methode de Traduction, Didier, Paris, 1977.

${ }^{14}$ La literatura española, en cuanto a traducciones se refiere, ha tenido un escaso mercado en el ámbito italiano. Durante muchos años la preferencia por autores franceses e inglese ha relegado el trabajo de traducción de obras españolas a un segundo plano. Aún así la mayoría de nuestros clásicos han ido adquiriendo un lugar importante dentro de la producción en italiano.

${ }^{15}$ Delibes, M. Signora in rosso su fondo grigio. Traducción y notas de Rosa Rita d'Acquarica, Firenze-Antella: Passagli editori, 1996.
} 
- De modismo a no modismo

Español

Italiano

... se lo cambiaré al Servicio Forestal pelo a pelo por esa casa. Pág. 11
.... comprerò un prato a Villarcayo e lo darò alla Guardia Forestale in cambio di questa casa. Pág .9

En este ejemplo encontramos la locución adverbial pelo a pelo. El diccionario fraseológico documentado del español actual ${ }^{16}$ nos define esta locución adverbial como: "Uno por otro, sin añadido de ningún tipo. Con el v. cambiar por otro de sentido equivalente....”. El ejemplo que nos presenta el diccionario es el mismo que hemos utilizado nosotros.

Aquí el traductor ha optado por una explicación de la locución, tomando la definición de: cambiar una cosa por otra cosa, darò alla Guardia Forestale in cambio di questa casa. Por tanto no añade ningún tipo de expresión idiomática.

\begin{tabular}{|l|l} 
Pero, además, fue la que dio en el & E per giunta, vide giusto. Pág . 26
\end{tabular} clavo Pág. 36

Dar en el clavo es una locución verbal que significa acertar ${ }^{17}$. El traductor ha optado por la expresión vide giusto realizando así una explicación del elemento y eliminando, de nuevo, la carga paremiológica.

- De modismo a modismo

En todos los casos el traductor ha optado por elegir la misma expresión puesto que existe en la lengua de llegada.

¿te das cuenta del ardid? Les alarmaba el cariz que iba tomando el proceso 1001; que la calle se les fuese de las manos. Pág.15
Ti rendi conto della malignità? Erano allarmati dalla piega che stava prendendo il processo 1001; temevano che la cosa sfuggisse loro di mano. Pág. 12

La definición de la locución verbal irse de las manos es: "No alcanzar[la] o atrapar[la] cuando estaba a punto de conseguirlo...”18

En italiano hemos tomado la definición del Nuovo Dizionario dei sinonimo della lingua italiana di N. Tommaseo. Firenze 1838:

1584. FUGGIRE, sfuggire, scappare, schivare, scampare. [...] Sfuggire di mano, in senso proprio è un cadere di mano. [...] Nel traslato dicesi di quelle cose, delle qualli a poco a poco ci va mancando la potestà.... ${ }^{19}$ (TOMMASEO, N. 1838, pág 404)

\footnotetext{
${ }^{16}$ Cfr. M. Seco, O. Andrés y G. Ramos, Diccionario fraseológico documentado del español actual. Locuciones y modismos. Ed. Aguilar, Madrid, 2004. Pág. 766.

${ }^{17}$ Ibíd., pág 288.

18 Ibíd., pág 617.

${ }^{19}$ N. Tommaséo. Nuovo Dizionario dei sinonimo della lingua italiana. Firenze
} 
Dentro de la definición de la palabra mano encontramos: "Sfuggire di mano, ( fig.) detto di situazione di cui si perde il controllo...,"20.

Analizadas ambas definiciones podemos afirmar la correspondencia de significado en ambas lenguas.

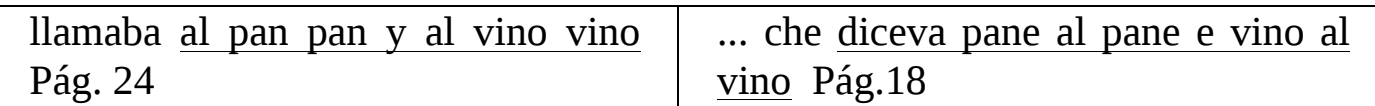

La expresión al pan, pan y al vino, vino se utiliza para "indicar que se habla o pedir que se hable, con toda franqueza o claridad...” (Seco, Andrés y Ramos , 2004, pág 729). En Italiano nos encontramos con la expresión dire pane al pane e vino al vino.

significa dire con molta chiarezza come stanno le cose, chiamare le cose con il loro nome senza sottintesi o eufemismi, essere molto chiari, precisi ....(PITTÀRO, 2001, pág 88).

Las dos expresiones significan decir algo con claridad y precisión. Aquí el traductor conocedor de la existencia de la misma expresión ha mantenido la misma estructura, ya que la lengua y cultura de llegada así lo permitían.

- De modismo a pérdida de significado ${ }^{21}$

Aquello fue la obra del Escorial. Pero había que ambientar los rincones. Pág. 48
Fu l'opera dell'Escorial ${ }^{5}$. Poi ci fu da ambientare gli angoli. Pág. 35

En el diccionario fraseológico encontramos la expresión la obra del Escorial o de El Escorial referida a "Cosa que tarda mucho en terminarse, especialmente por ser muy laboriosa” y encontramos el mismo ejemplo sacado de esta obra de Delibes. En el texto el autor, además, ha utilizado esta expresión para comparar las obras de una cocina con la realización del Escorial. El traductor ha reproducido la misma expresión y ha explicado en una nota que es El Escorial:

El Escorial, o San Lorenzo del Escorial, è la reggia voluta da Filippo II, la cui costruzione, avviata nel 1563 su progetto di Juan Bautista da Toledo fu terminata nel 1584, sotto la direzione di Juan de Herrera. Imponente ed austero, il complesso comprede una chiesa (sul modello di San Pietro a Roma) un convento dei padri agostiniani, e il palazzo reale, decorato lungo i secoli XVII e XVIII, dai successori di Filippo II.

Esta nota del traductor hace referencia a la estructura de todo el complejo del monasterio y a la magnitud de la obra arquitectónica pero no añade el dato de que además es una expresión coloquial. En este caso si el traductor conocía alguna expresión en la lengua de llegada que no tuviera el ámbito de la construcción como referente, se descompensaría toda la estructura interna del discurso, puesto que per-

\footnotetext{
${ }^{20}$ Cfr. Dizionario Italiano, Ed Garzanti, Milano, 2001, pág, 1280.

${ }^{21}$ Este caso no corresponde al tercer tipo ilustrado por Nida y Taber.
} 
dería la comparación de unas obras de remodelación en una cocina con la construcción del Escorial. Por tanto la solución de traducir directamente la expresión, aunque conlleve perdida semántica, permite mantener la coherencia del discurso.

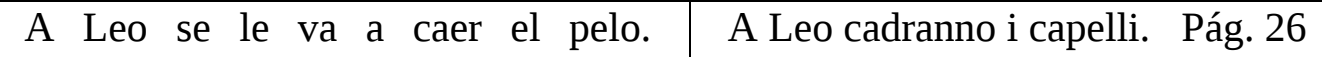
Pág.36

Caérsele el pelo a alguien es una expresión con significado negativo. "Recibir un castigo fuerte o sufrir una consecuencia negativa grave..."22 Hemos buscado en el Dizionario dei modi di dire y no aparece reflejada ninguna expresión que sea cadere capelli. Hemos ampliado la búsqueda con el Dizionaro Italiano Garzanti, el diccionario enciclopédico on-line Treccani, en el N. Tommaseo. En ninguno de ellos hemos encontrado la acepción que toma la locución verbal en español. Aparece la frase cadere i capelli con el significado estricto de caída de pelo.

En este caso, la traducción ha perdido el matiz de negatividad, de reprimenda y castigo que poseía el texto en origen y, por lo tanto, da lugar a una confusión de significado puesto que Leo no va a perder el pelo progresivamente sino que sufrirá un castigo por sus actos.

Como hemos podido observar en estos ejemplos el resultado final de la acomodación de la obra literaria a otra cultura y otra lengua depende, muy estrechamente, del grado de conocimiento del traductor y de las reflexiones y decisiones que tomó al verter el contenido semántico a la lengua meta. Los elementos paremiológicos deben tener el mismo significado en ambos idiomas o de lo contrario podríamos generar equívocos interpretativos. La opción de simplificar la estructura cuando no se conoce en la lengua de llegada un elemento parecido supone recuperar un significado que podría perderse y por el contrario forzar una estructura que no significa nada en la lengua de partida podría ocasionar extrañeza e interpretaciones erráticas. Algunos elementos paremiológicos, como el caso de la obra del Escorial, poseen ya información pertinente para su entendimiento. La nota final que nos explicaba de que tipo de construcción se trataba añade el referente dentro de una cultura donde no todos tienen por que saber que es El Escorial. El resultado final, tras leer la nota, es la presentación de una construcción de tal magnitud que se acercaba al carácter de exageración que el autor había querido reflejar en el texto.

Proponemos siempre optar, en la medida de lo posible, por un respeto, cuándo la estructura lingüística no produzca extrañamiento, de las formas originales, aunque en otras ocasiones la carencia de equivalencia de una expresión en la lengua de llegada obliga a realizar una simplificación de la estructura para optar por la comprensión y favorecer, en ciento modo, un tipo de lectura más fluida y coherente con los lectores a los que va dirigida la obra. Consideramos además que la Interpretación Gramatical debe ir, siempre, en las obras literarias, acompañada de la Interpretación Alegórica ya que muchos textos presentan problemas interpretativos derivados de los cambios en la sociedad y la transposición cultural, es decir, están directamente ligados a la recepción de ciertos conceptos en un entorno cultural diferente, y esto lo vamos a poder verificar en el caso de los elementos paremiológicos.

\footnotetext{
${ }^{22}$ Op. cit. Diccionario fraseológico, 2004, pág 765
} 


\section{Conclusiones}

Para concluir recordamos que, según la definición de traducción como proceso intercultural, una de las dificultades interpretativas a las que se enfrenta el traductor proviene de estas regiones culturales adscritas a la identidad propia de un pueblo o de una región y distintas, en algunos casos, de las manifestaciones populares del entorno cultural nuevo que acogerá la traducción. El traductor, con todas las herramientas y procesos analizados y puestos a su disposición, se convierte en "autor” intentando, mediante el dominio del lenguaje, plasmar una serie de artificios típicos de una personalidad literaria muy concreta, para, de esta forma, lograr conseguir un efecto similar al que percibió en la fase de simple lector.

No debemos olvidar que, muchas veces, el traductor no puede tomar las mismas decisiones transgresoras que sí se permite el creador del texto original, el autor literario, ya que puede llegar a crear una serie de formas estructurales carentes de sentido en la cultura receptora y caer así en la inducción a errores por falta de comprensión o conocimiento del texto, entre otras cosas. La complejidad de esta operación se incrementa con la aparición de dichos elementos culturales ya que además de ser un buen conocedor de la lengua y de la cultura en la que se inserta el texto de partida, el traductor para poder reconocerlos deberá estar familiarizado con ciertos datos pertenecientes, en algunas ocasiones, a una cultura muy restringida. Por tanto, si se encuentra con falta de conocimiento en este campo cultural y folclórico, deberá documentarse para llegar a entender algunos conceptos. Esta operación supondrá un doble trabajo de investigación para el traductor, que ya además de enfrentarse a las labores documentales típicas de una traducción para contextualizar el texto, ahora además deberá documentarse para conocer y poder reproducir las ideas y conceptos que recogen los elementos paremiológicos, función, significado, registro, etc.

El lector, en muchas ocasiones, desconocedor de la lengua original en la que se escribió la obra va a leer la traducción como si de la obra original se tratase, olvidando al traductor y lo que conlleva una “interpretación” del texto de partida.

Por consiguiente, la fase de interpretación es fundamental para adquirir un entendimiento, lo más completo posible, de la obra en cuestión. Es muy difícil resolver los problemas concretos que presentan los elementos paremiológicos e intentar sentar unas bases para poder estructurar los aspectos crítico-estilísticos, que se deberán tener en cuenta, al afrontar el trasvase de este tipo de información. Por ello pensamos que se requiere un trabajo basado en metodologías de análisis semántico y crítica textual. Las diferentes funciones semánticas que puede adquirir un texto junto con la intencionalidad del autor serán puntos fundamentales que el lectorintérprete de la obra, en este caso el traductor, deberá tener en cuenta en una primera instancia. El momento de creación artística es donde se encuentran todas las concepciones y premisas que el escritor poseía y que están bajo un código interpretativo; este código es el que, con ayuda de las directrices y procedimientos de análisis (distintas técnicas de adaptación de elementos paremiológicos) y los planteamientos teóricos expuestos, el traductor tratará de comprender y acomodar a la lengua de llegada.

Salud Marilla

smjarilla@ucm.es

IULMyT, Universidad Complutense de Madrid 


\section{Referencias bibliográficas}

DeliBes, Miguel. Señora de rojo sobre fondo gris. Barcelona: Ed. Destino, 1991. . Signora in rosso su fondo grigio. Firenze-Antella: Passagli editori, 1991, $110 \mathrm{p}$.

FÉRNANDEZ, Leandro F. El papel de la cultura en el proceso traslativo y en la formación del traductor. En: Isabel Cómitre Narváez, Mercedes Martín Cinto, Traducción y cultura. El reto de la transferencia cultural, Málaga: Encasa, 2002, 263 p.

FÉRnANDEZ-SEVILLA, Julio. Consideraciones lexicológicas y lexicográficas sobre el refranero en: Estudios Románicos dedicados al profesor Andrés Soria Ortega, Ed. Universidad de Granada, Granada, 1985.

GARCiA YeBRA, Valentín. Teoría y práctica de la traducción. Vol I. Madrid: Gredos, 1997. $408 \mathrm{p}$.

Hatim, Basil y Mason, Ian. Teoría de la traducción. Una aproximación al discurso, Barcelona: Ariel, 1995, 332 p.

LEFEVERE, André. Traducción, reescritura y la manipulación del canon literario. Salamanca: Ediciones Colegio de España, 1997, 246 p.

MENDOÇA DE LIMA, Lucielena. La traducción de los modismos en la enseñanza del español como lengua extranjera. ASELE. Actas VIII. Centro Virtual Cervantes. 1997, Disponible en:

www.cvc.cervantes.es/ensenanza/biblioteca_ele/asele/pdf/08/08_0567.pdf

Acceso: 24 de enero de 2014.

NIDA, Eugene y TABER, Charles Russell. La traducción teórica y práctica, Madrid: Ediciones cristiandad, 1986, 255 p.

PitTÀno, Giuseppe. Dizionario dei modi di dire, proverbi e locuzioni. Bologna: Zanichelli, 2001, 352 p.

SCELfo, Maria Grazia. Tradurre L' “Atro": Tra ideologia e manipolazione, en: Giuliana Garzone, Laura Salmon y Luciana T. Soliman. Multilinguismo e Interculturalità. Confronto, identità, arricchimento Atti del convegno Centro Linguistio Bocconi, (Milano 20 ottobre 2000), Milano: LED, 2007, 205 p.

SECo, Manuel, ANDRÉs, Olimpia y RAMos, Gabino. Diccionario fraseológico documentado del español actual. Locuciones y modismos. Madrid: Ed. Aguilar, 2004. $1084 \mathrm{p}$.

SzONDI. Introducción a la hermenéutica (1975). Madrid: Abad Editores, 2006, 258 p.

TOMmASEO, Niccolo. Nuovo Dizionario dei sinonimo della lingua italiana. Firenze: Pietro Vieusseux, 1838, 1140 p.

TORREs, Esteban. Teoría de la traducción literaria. Madrid: Síntesis, 1994, pp. 127-138.

TreCCANI. Dizionario on-line. Disponible en: http://www.treccani.it/vocabolario/ Acceso: 24 de enero de 2014.

VV.AA. Dizionario Italiano, Milano: Garzanti, 2001, 2598 p.

VIDAL, M ${ }^{\mathrm{a}}$ Carmen. Traducción, manipulación, deconstrucción, Salamanca: ed. Colegio de España, 1995, 135 p.

VINAY Jean-Paul y DARBELNERT Jean. Stylistique comparée du français et de l'anglais. Methode de Traduction, Paris: Didier, 1977. 331 p. 